\title{
Attitudes towards student support: How positive feedback-effects prevent change in the Four Worlds of Student Finance
}

\author{
Julian L Garritzmann \\ University of Konstanz, Germany
}

\begin{abstract}
This article provides a detailed analysis of individual preferences towards public financial aid to students from low-income families. Who favours/opposes such aid? What are the determinants of the respective preferences? I argue that three sets of factors jointly shape these preferences: materialistic self-interests, political attitudes, and the status quo of the higher education subsidy systems by generating positive feedbackeffects. Results of multilevel ordered logit models utilizing the International Social Survey Program (ISSP) data for up to 22 countries over two decades indicate that self-interest matters: students strongly favour subsidies as do their parents, while those paying for the spending and those not expecting to benefit oppose such aid. Moreover, political attitudes are important: Supporters of redistribution and of increased public education spending in general, as well as leftwing voters, are much more likely to support students. On the macro-level, the findings suggest that positive feedback-effects exist: in countries with generous subsidy systems, public support for subsidies is higher. This article is the first to systematically analyse preferences towards higher education subsidies across countries and time and demonstrates how positive feedbackeffects increasingly lock-in countries' tuition-subsidy paths, making the systems resistant to (radical) change. As such, it speaks to the literature on the political economy of skill formation, the welfare state, public opinion and the public opinion-policy link.
\end{abstract}

\section{Keywords}

Attitudes, political economy of skill formation, higher education, feedback-effects, social policy, student support

\section{Introduction}

When a student graduates from college in the United States, she probably shoulders a debt of US $\$ 40,000$, due to loans she took out to cover tuition fees and living expenses. Even amounts exceeding US $\$ 100,000$ are not uncommon (Martin and Lehren, 2012).

\section{Corresponding author:}

Julian L Garritzmann, Department of Politics and Public Administration, University of Konstanz, Fach D79, Konstanz, BW 78457, Germany.

Email: julian.garritzmann@uni-konstanz.de 


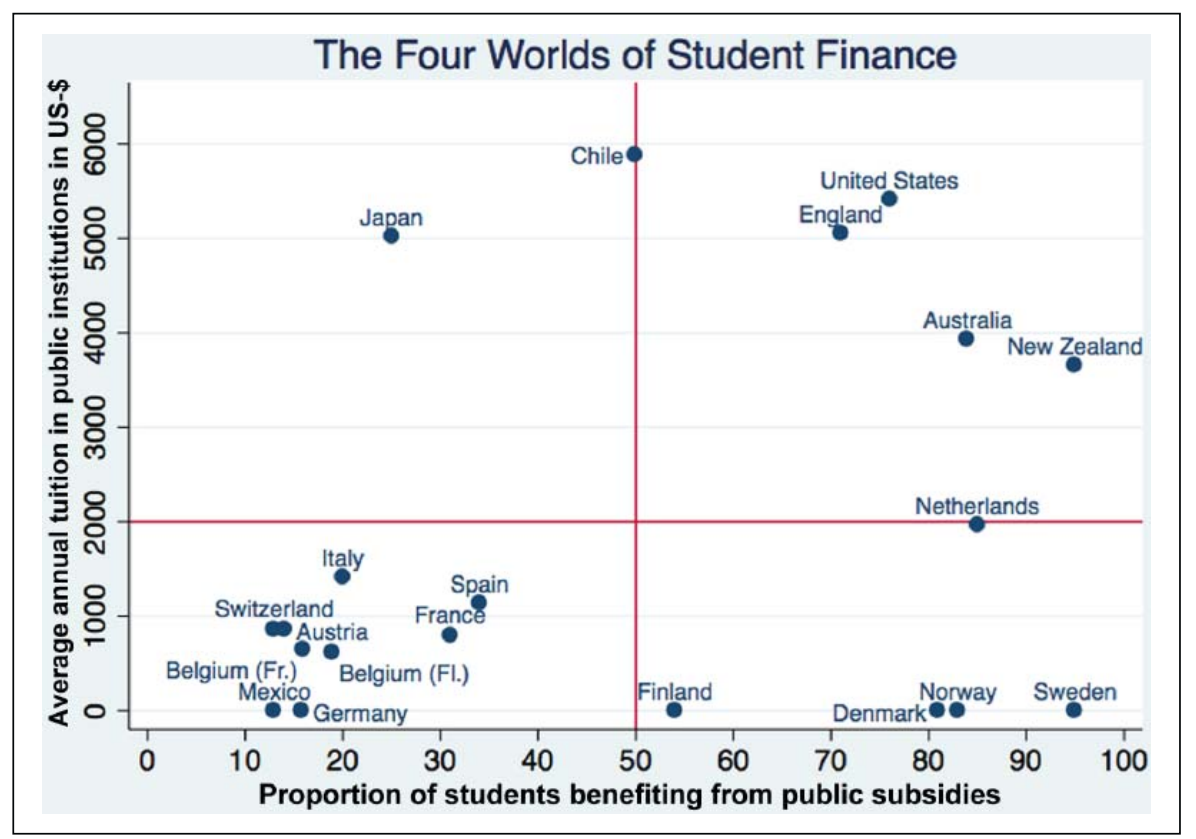

Figure I. The Four Worlds of Student Finance.

Source: Author's compilation, based on Organisation for Economic Co-operation and Development (OECD; 2013). All data are for the year 2010, except for Japan and Spain, where data on the proportion benefiting was only available for 2004. For Germany, I added own estimations based on data from the German Federal Ministry of Education and Research (BMBF).

Suppose this student (let us call her Hannah) had studied in Denmark instead. Here, Hannah would have paid no tuition fees at all, and probably she would have received a considerable public grant to cover living costs during her studies. We can also imagine that Hannah studied in Berlin where no tuition would have been charged either - presumably, however, she also would not have received any public financial support. Finally, consider Hannah studied in a typical Japanese university. The amounts charged would be similar to those in the United States; in contrast to the United States, however, public financial support would hardly be available. ${ }^{1}$

As these four ideal-typical scenarios illustrate, the advanced democracies' tuition-subsidy systems differ tremendously. In fact, 'Four Worlds of Student Finance' can be distinguished (Garritzmann, 2014: Chapter 2). Figure 1 illustrates these by depicting two exemplary characteristics of tuition-subsidy systems: average annual tuition amounts and the proportion of students receiving subsidies. In the bottom left of Figure 1, the continental European countries cluster in a low-tuition-low-subsidy regime. In the bottom right, a low-tuition-high-subsidy system appears, comprising Nordic Europe. The AngloSaxon countries fall into a high-tuition-high-subsidy world in Figure 1's top right corner. Finally, we also find the combination of high tuition and low subsidies in some Asian and Latin American countries. ${ }^{2}$

Historically, however, countries developed their tuition-subsidy systems - just as their welfare states (Esping-Andersen, 1990; Huber and Stephens, 2001) - from an almost identical starting point: in the immediate postwar-time, all OECD-countries had very low higher education enrolment levels (Windolf, 1997), low tuition and no public student support systems (Nakata and Mosk, 1987). As I have shown elsewhere (Garritzmann, 2014), countries' developments from this low-tuition-low-subsidy (lowenrolment) starting point to today's distinct Four Worlds of Student Finance can be explained by the partisan composition of government and especially the sequence and duration in which parties of the left and right controlled office. What remains puzzling, 
however, is the stability of the Four Worlds during the more recent decades: although parties exercised enormous influence on the development of the tuition-subsidy systems during the $1950 \mathrm{~s}-1980 \mathrm{~s}$, the recent decades have witnessed much less radical change. Rather, countries have followed along their respective paths: high-tuition countries kept increasing tuition, while low-tuition countries kept tuition low. Likewise, countries with generous subsidy systems maintained or extended these, while low-subsidy states did not undergo significant expansion. In fact, it seems that no country has witnessed radical change in its tuition-subsidy regime after important decisions were made in the immediate postwar dec$\operatorname{ades}^{3}$ (Garritzmann, 2014 and Figure A in Online Appendix).

The aim of this article is twofold. First, it offers an explanation for why the Four Worlds of Student Finance have become so resistant to (radical) change. I argue, in line with key contributions in the historical institutionalist literature (Campbell, 2012; Kumlin and Stadelmann-Steffen, 2014; Pierson, 1993, 1994, 2000, 2006; Skocpol, 1992; Thelen, $1999,2004)$, that this is so because the existing tuition-subsidy regimes create strong positive feedback-effects on the individual level, increasing support for the respective existing tuition-subsidy systems. These preferences make (radical) change increasingly costly for political parties, which is why path dependencies prevail. As I show below, this follows from both rational choice and sociological perspectives.

As the literature review will demonstrate, individual-level education policy preferences have hardly been studied. A second objective of this article is therefore to offer a comprehensive study of the determinants of attitudes towards higher education policies, testing the influence of three customary groups of explanations: materialistic self-interest, political attitudes and institutional contexts, that is, feedbackeffects. In the empirical analysis, I concentrate on attitudes towards subsidies (and disregard attitudes towards tuition) for theoretical and empirical reasons discussed below. This article thus addresses three questions: who favours/opposes subsidies? What are the determinants of the respective preferences? Does the existing subsidy-regime have positive feedback-effects on citizens' attitudes, generating support for the status quo? Questions posed in three ISSP-waves provide data for attitudes towards spending for students from low-income families for up to 22 countries over two decades. While not a panel dataset in a strict sense, we can treat the data as a 'quasi-panel' and analyse whether, how and why attitudes have changed during the last two decades.

The results of multilevel ordered logit models reveal on the micro-level that self-interest and political attitudes matter. On the macro-level, the findings suggest that positive feedback-effects are at work, because public opinion becomes more favourable of student support, the more generous the existing support systems. These findings are robust against a large number of tests.

Understanding attitudes towards higher education policies is highly relevant for theoretical and societal reasons. The societal relevance of these phenomena hardly needs emphasis, as the tuition-subsidy regimes have enormous (re-) distributional consequences and shape - among other things - the (acceptance of) socio-economic inequality, redistribution and social mobility, the general skill profile of a country, and thereby even its type of capitalism. This article is theoretically relevant, as our knowledge on individual preferences towards education policies is still crude due to scholars' focus on macro-level explanations and because of a poor data situation (full references below). Without investigating the underlying micromechanisms of macro-phenomena, however, political economy analyses lack their crucial backbone.

This article proceeds in the usual fashion: a literature review is followed by my theoretical framework. The section on 'Research design' is followed by the 'Results' section which presents empirical results, while the next section probes their robustness. The final section concludes and sketches promising extensions for further research.

\section{Literature review}

Whereas education has been a central theme in sociology, psychology, economics and education science already for decades, political scientists have only recently developed an interest in education policies and education systems - often under the headings of 
'skill formation' or 'human capital investment' (Busemeyer and Trampusch, 2011; Iversen and Stephens, 2008; Jakobi et al., 2009). Several core contributions to the field have pointed out the fundamental importance of patterns of skill formation for politico-economic systems. Most prominently, the Varieties of Capitalism (VoC) approach (Hall and Soskice, 2001), which led to a paradigm shift in the political economy and the welfare state literatures, places skill formation at the core of politicoeconomic systems by demonstrating that neither production regimes, nor welfare states, nor social policies, nor demands for or supply of redistribution, nor the effects of structural changes such as globalization, deindustrialization or skill-based technological change can be understood without taking into account the design of the education systems (Estevez-Abe et al., 2001; Iversen, 2005).

The lion's share of these newer studies has focused on the role of collective actors, especially political parties (Ansell, 2010; Boix, 1997; Busemeyer, 2009; Castles, 1982; Iversen and Stephens, 2008; Schmidt, 2007) as well as the interaction of employers and unions (Busemeyer and Trampusch, 2011; Iversen and Stephens, 2008; Thelen, 1999, 2004). Analyses of individual preferences, in contrast, are extremely rare. Only a handful of publications have focused on attitudes towards education policies in a comparative context. ${ }^{4}$ Whereas Estevez-Abe et al. (2001) theorized already in the original $\mathrm{VoC}$ volume (Hall and Soskice, 2001) on individual-level education preferences, a first comparative empirical analysis of attitudes was conducted by Busemeyer et al. (2009). The authors questioned whether income or age was more important in explaining welfare-state attitudes and theorized that the explanatory power might differ across policy fields, because the likelihood of receiving specific benefits varies by age and income. Empirical analyses of ISSP-data confirm that age is a stronger determinant of education spending preferences than income: the elderly are more reluctant to increase education spending and favour expenditure on pensions instead, possibly because neither they nor their children are expecting to receive public education anymore.

In addition to these studies focusing on micro-level explanations of individual-level education policy preferences, two recent studies add macro-determinants: Busemeyer (2012) investigates how socioeconomic and educational inequalities affect attitudes towards education policies, and Busemeyer and Jensen (2012) studied the effects of economic coordination and of the status quo of the vocational education and training (VET) system on attitudes over public education spending.

While the previously discussed studies all focus on education policy preferences in very general terms (i.e. 'more or less spending on education'), more fine-grained analyses were conducted by Ansell (2010) and Busemeyer et al. (2011). Ansell (2010) concentrates on preferences towards financial support of higher education students from lowincome families (utilizing the same operationalization as my study). He argues that individual (and party) preferences are conditional on the status quo of the education system, especially the level of tertiary enrolment: in brief, Ansell posits that when enrolment is low, rightwing voters/parties favour (and leftwing voters/parties oppose) public education spending, because the right's constituency is more likely to benefit from this spending as access is empirically stratified by income. Yet, Ansell expects that when enrolment levels soar and reach a certain threshold, party positions flip, as further expansion would grant access to lower-income groups. At this point, leftwing parties are expected to favour (and rightwing parties to oppose) further expansion.

Ansell (2010) uses survey-data from the 1996-ISSP-wave to probe these claims on the microlevel. He reports an 'extremely robust' (p. 185) effect of income: the richer the individuals, the higher their opposition to financial assistance to low-income students. Moreover, ideology matters, as left-leaning individuals favour subsidies while rightwing respondents tend to oppose such assistance. Finally, empirical evidence is presented for his main argument: high-income and rightwing respondents are even more opposed to subsidies when tertiary enrolment is high.

To date, Ansell's study is the only comparative study of attitudes towards financial support of students and as such receives much praise. Yet, his analysis can be extended in several respects. First, Ansell only tests very few possible determinants, leaving it 
an empirical question whether the results remain robust when controlling for rival explanations. Second, although data are also available for additional years, Ansell surprisingly does not use all available data. It is thus highly interesting to explore whether his results can be reproduced using data for other time-points and other operationalizations. Third, Ansell does not analyse whether the existing tuitionsubsidy regimes feed back on individual preferences as theorized here. Finally, one can criticize Ansell's analysis from a methodological point of view as he tests a multilevel argument (including even crosslevel interactions) with a single-equation model. Hence, it should be tested whether the results remain robust in more elaborated (multilevel) analyses.

A second fine-grained study of individual education policy preferences was conducted by Busemeyer et al. (2011). The authors exploit a survey carried out in Switzerland in 2007, which is unique because it mainly posed questions about individual education policy preferences. Busemeyer et al. find that individuals' educational backgrounds and incomes are important determinants of policy preferences concerning the distribution of public expenditure across different education sectors. In addition, socialization effects seem to be at work, as respondents support that type of education that they themselves attended. Educational background and income lose their explanatory power, however, when it comes to preferences towards the relationship between public and private spending. Instead, ideology turns out as the dominant explanation: left-oriented individuals demand larger spending from the public and smaller contributions from students. Right-leaning respondents, in contrast, favour lower public, but higher private contributions. Finally, the status quo of the education system matters; that is, in Cantons where vocational education and training (VET) plays a prominent role, support for more spending on this sector is also larger.

Whereas the study of Busemeyer et al. (2011) is the first encompassing analysis of individual education policy preferences, it falls short in two respects. First, it remains unclear whether we can generalize from the findings to respondents in other countries or at other points in time. Second, while the authors analyse preferences towards tuition fees, no analysis of preferences over financial student support is included.

In sum, political scientists have only recently developed a strong interest in education policies and education systems. As their focus has remained on collective political actors, however, only a handful of studies have analysed individual attitudes towards education policies in a comparative setting. Moreover, most of these studies have focused on very general preferences (towards either more or less public education spending) and do not inform us about more specific areas such as higher education finance. Consequently, our knowledge about attitudes towards higher education finance is still very crude.

\section{What explains attitudes towards financial student support?}

What explains attitudes towards financial support of students? Following the literature on individual social policy preferences, I derive hypotheses from three groups of explanations: materialistic self-interest, political attitudes and institutional effects of the macrocontext. While all three sets of explanations are highly interesting in themselves, the latter explanation is especially relevant for the present purpose, as I claim that positive feedback-effects help explain path dependencies in the Four Worlds of Student Finance.

\section{Materialistic self-interest}

Self-interest - that is, achieving one's highest benefit/cost ratio - has been used as (one of) the main explanations for individual policy preferences (e.g. Kangas, 1997; Van Oorschot, 2006), at the latest since rational choice has become a leading paradigm in social science. Assuming a rational individual, we can expect that those who (expect to) benefit from subsidies, that is (future) students, will be supportive. Vice versa, those, who do not (expect to) receive benefits and those who pay for these services, will oppose such spending. Thus,

$\mathrm{H} 1$ : Current and prospective students strongly favour public subsidies. Taxpayers, that is, respondents in (full-time) paid-work, strongly oppose subsidies. 
Related to this, income is likely to shape attitudes towards subsidies, for two main reasons: first, the higher one's income, the higher the tax amount and hence the more likely the opposition against public subsidies. A second reason is more psychological: the higher one's income, the lower the incentiveeffect of subsidies. Countless studies have shown that children from low-income backgrounds are more debt- and risk-averse (e.g. Archer et al., 2003; Callender and Jackson, 2005) and that subsidy systems have significant effects on their enrolment and studying behaviour (Curs et al., 2007; McPherson and Schapiro, 2006). The lower one's income, the higher the (perceived) value of subsidies. Hence, while higher income groups might favour spending on tertiary education institutions (because they are more likely to enrol), they will not favour spending on student aid, because they are unlikely to benefit.

H2: The higher a respondent's (household) income, the lower her or his support for subsidies.

In addition to these straightforward self-interest hypotheses, another more indirect dimension of selfinterest might exist: parents of students might share their children's preference towards subsidies, either because they aim to reduce their own costs (as parents often cover their children's education costs) or because they want to reduce their offspring's financial burden. Hence, we can expect that having children who study increases one's support for subsidies. Unfortunately, this proposition is impossible to test directly because no comparative survey includes questions on whether one's children study - let alone receive subsidies. One could, of course, simply assume that all parents have similar preferences. This assumes, however, that the expectation of all parents for their children to receive higher education is equal. As this is empirically unlikely to hold, I reverse the perspective and expect

H3: Adults, who do not have children, oppose subsidies. ${ }^{5}$

\section{Non-materialistic determinants}

Besides materialistic self-interest, a second classical set of explanations of attitudes points at the impact of non-materialistic influences, such as norms, values, ideologies and socialization effects. To begin with, it is reasonable to expect socialization effects, that is, individuals' education policy preferences are likely to depend on their own education experience. Busemeyer et al. (2011) find, in this vein, for Switzerland that individuals who attended higher education are more likely to favour larger tertiary education spending, while former VET students favour expansion of VET-spending. That is, even if not benefiting from subsidies themselves anymore, former students might favour subsidies.

H4: Individuals who received higher education (specifically those who hold a higher education degree) favour subsidies more than individuals without higher education experience.

Second, individuals' ideological positions are highly likely to affect their policy preferences. There is much debate in the political economy of skill formation literature on whether education spending is favoured by leftist or rather by rightist individuals and parties (Busemeyer et al., 2013 provide a detailed discussion): some scholars claim (Boix, 1997; Busemeyer, 2009; Castles, 1982; Iversen and Stephens, 2008; Schmidt, 2007) that public (tertiary) education spending fosters social mobility, equality of opportunities and redistribution, and deduce that it is therefore favoured by leftwing voters and parties. In contrast, others claim that (tertiary) education particularly benefits higher income groups as access is de facto stratified by income (Blossfeld and Shavit, 1993; Breen and Jonsson, 2005), making (higher) education spending essentially regressive. Consequently, it should be favoured by high-income, rightwing voters (Ansell, 2010; Fernandez and Rogerson, 1995; Jensen, 2011). Thus, the literature offers conflicting hypotheses on effects of ideological positions on public (higher) education spending. When we concentrate more narrowly on financial aid to (low-income) students, however, these contradictions can easily be resolved, as this spending is targeted to needy students and consequently strongly redistributive. Hence, I posit,

H5: Leftwing-oriented individuals support and rightwing individuals oppose financial support of 
(low-income) students. This relationship is the stronger, the more extreme the individual's ideological position (linear effect).

Finally, respondents' preferences towards subsidies might be related to their general view on redistribution because education policies and social policies are adjacent policy fields: an individual is more likely to support subsidies when she also favours redistribution. This is particularly likely in this study, because the used survey-item focuses specifically on students from 'low-income families' (see discussion below). Hence, I expect

H6: Individuals, who demand more redistribution, are more likely to support subsidies (for low-income students).

\section{Macro-level determinants: Feedback- effects}

The third group of determinants - and the one of particular interest here for the broader argument on the sustainability of the Four Worlds of Student Finance - highlights the influence of institutions. A recently rapidly growing literature has argued - following Pierson's (1993, 1994, 2000, 2005, 2006) seminal contributions - that institutions can generate 'feedback-effects', that is, shape actors' preferences (Campbell, 2012; Kumlin and Stadelmann-Steffen, 2014; Skocpol, 1992; Thelen, 1999, 2004). Pierson (1993) distinguishes feedback-effects on three levels (mass public, interest groups and elites) through two mechanisms (incentive effects and interpretive effects), thus leading to six types of feedback-effects (Pierson, 1993: Figure 1). In this study, I focus on feedback-effects on the mass public and on elites and show that both mechanisms lead to the expectation of positive feedback-effects in the present context. ${ }^{6}$

While the original contributions in this literature all expected positive feedback-effects (i.e. institutions generating their own support), more recent studies emphasized that negative feedback is also possible, that is, institutions undermining themselves (Fernández and Jaime-Castillo, 2013; Jacobs and Weaver, 2014; Weaver, 2010). The effects might even be more complex, following, for example, a 'thermostatic model' with differing short-term and long-term feedback-effects, as theorized by Wlezien (1995; compare also Soroka and Wlezien, 2010; Wlezien and Soroka, 2012).

Ansell (2010), Busemeyer et al. (2011), Busemeyer and Jensen (2012), Mettler (2002) and Mettler and Welch (2004) applied these arguments to education policies and investigated effects of education systems on individual-level preferences, as summarized in the literature review. In line with these studies, I expect the institutional set-up of the higher education systems, especially the generosity of the subsidy systems, to affect attitudes towards student support. Theoretically, we can deduce expectations about both positive and negative feedback-effects: for example, are individuals in countries with universal subsidy systems in favour of maintaining and expanding these systems (positive feedback), or are they 'fed-up' with the large and costly support and want to retrench spending (negative feedback)? Yet, I argue that positive feedback is much more likely in the case of student support. This follows from both 'metatheories' of individual behaviour, that is, from rational choice (Pierson's 'incentive effects') and from sociological approaches (Pierson's 'interpretive effects').

Starting with the latter perspective, we can assume that the individuals' perception of subsidies affects their perceptions of fairness, social mobility and equality of opportunities. Consequently, individuals who (have not) benefited from public subsidies will also find it just that others in the same situation equally (do not) receive such support. Thus, as the generosity of subsidies increases, an increasing share of the population can be expected to favour (further expansion of) subsidies, whereas where they are sparse, support for subsidies can be expected to be lower.

The same conclusion follows also from a rational choice perspective: extending the materialistic selfinterest hypotheses (Hypotheses 1-3), individuals' support will increase as the subsidies' generosity increases. More specifically, public support for subsidies will be the higher, the higher the received subsidy amounts, the larger the proportion of 
students benefiting, and the more generous the repayment conditions (i.e. the larger the grant visà-vis the loan component). Moreover, while one could argue that individuals might oppose subsidies once they graduated because they are not likely to benefit themselves anymore, several other arguments speak against this 'time-inconsistency problem': the more generous the subsidy systems, the more likely it is that close relatives (e.g. their children) might benefit in the future. Additionally, respondents might find it even economically valuable that (needy) students are supported financially, because otherwise human capital is wasted, leading to economic decline (in the long-run). Thus, positive feedback-effects can be deduced from a rational choice and from a sociological perspective, that is, from both of Pierson's (1993) mechanisms. ${ }^{7}$ In sum,

H7: The more generous the existing subsidy system, the higher the public support for subsidies. That is, (a) higher public spending on subsidies, (b) larger proportions of students benefiting, (c) higher subsidy amounts received by students, and (d) larger shares of grants vis-à-vis loans increase public support for subsidies.

These positive feedback-effects on the individuallevel, in turn, can be expected to have effects on policy-makers (Pierson's 'elite-level feedback'), particularly political parties, who - irrespective of whether we conceive of them as policy- or as officemaximizers - also have to maximize votes (Müller and Strøm, 1999). Several scholars demonstrated how public opinion influences elites' policy-making and shapes their room to manoeuvre (Brooks and Manza, 2006a, 2006b; Kenworthy, 2009; Rehm, 2011; Soroka and Wlezien, 2010; Wlezien and Soroka, 2012). This is also likely for higher education subsidies, because as the cumulative share of beneficiaries grows over time (as enrolment levels soar), it becomes increasingly difficult for parties to retrench the services. To see this, imagine a rare illness, say - due to current events - Ebola. As long as only a tiny proportion of the population is affected, the population at large will hardly notice - let alone care about or invest time or money in - the topic. Yet, as soon as the illness spreads, suddenly a large proportion of the population becomes attentive and highly engaged in the topic. Substitute higher education for Ebola and that is exactly what I argue has happened with higher education.

In the 1950 s - in some countries even in the 1970 s - less than 5 in a 100 children saw a higher education classroom from the inside in any of today's advanced democracies. Higher education was a privilege of a very small elite (Windolf, 1997). Accordingly, the topic was hardly salient for the general public. As enrolment levels soared (mainly due to increases in subsidies), however, the group directly (i.e. students) and indirectly affected by higher education (e.g. students' families, workers in the higher education sector) grew tremendously in size. Over the years, the cumulative share of the population who had participated in higher education increased rapidly, empirically often exponentially (Windolf, 1997). Consequently, higher education (finance) continually became more salient in people's perceptions and in the public discourse. Because of this growing salience (Pierson would label this 'visibility') and people's clearer preferences (whereas before they were often inattentive to higher education), policy-makers' room to manoeuvre decreased constantly, as they had to pay more and more attention to the public's preference over the topic. That is why I argue that individual preferences become more (and party preferences less) important over time in understanding the politics of higher education finance, whereas the reverse was true when higher education systems were still in their infancy.

In sum, I expect that positive feedback-effects emerge from the existing subsidy systems and that these help to explain path dependencies in the Four Worlds of Student Finance.

\section{Controls}

On the micro-level, I control for respondents' age and gender. ${ }^{8}$ Moreover, respondents' preference towards public education spending and towards public spending in general are added, because it might be the case that someone does not specifically favour or oppose education spending, but public spending in general. On the macro-level, one can think of a variety of 
possible controls (countries' economic situation, demographic demand for public education, the type of tax system, etc.). Due to the small number of cases on the macro-level (maximum 22 countries), however, I have to concentrate on the theoretically most relevant explanations and cannot incorporate many rival explanations (Stegmueller, 2013).

\section{Research design}

This article investigates attitudes towards student support, focusing particularly on macro-level feedback-effects. Thus, comparative survey-data is needed, covering cross-national and cross-temporal variation. Unfortunately, data on education policy preferences is very scarce in the existing comparative surveys and questions on specific aspects almost entirely missing. The ISSP, however, included questions in its Role-of-Government (RoG) modules, which can be made fruitful for my purpose. In three RoG-waves (1990, 1996, 2006), respondents were asked

On the whole, do you think it should be or should not be the government's responsibility to give financial help to university students from low-income families? (ISSP Research Group, 2008)

The question thus allows investigating attitudes towards student support across up to 22 countries over two decades for roughly 50,000 respondents. Nevertheless, while offering the best available comparative data, the question-framing is not ideal for three reasons: first, the focus on students from 'lowincome families' draws attention from general support of students to a specific need-group. This is problematic because respondents might hold different opinions for support of students in general and for support of low-income students in particular. Moreover, respondents might hold certain positions for different reasons. For example, some individuals (especially in countries with generous subsidy systems) might oppose the statement simply because they think that all students, and not only low-income students, should be supported. ${ }^{9}$ Relatedly, the 'lowincome'-focus might lead respondents to interpret the question to be less about education subsidies and rather about redistribution in general. Thus, particular attention is necessary to keep attitudes towards student support and attitudes towards redistribution apart. To foreshadow the results, however, both items are rather weakly correlated $(0.4$; see Table A in Online Appendix); that is, while careful interpretation is necessary, the problem is empirically much smaller. It is not the case that the 'lowincome' supplement makes the item a simple 'redistribution-question', as critical readers might suspect.

Second, the question is not ideal as it focuses on 'university students' and not on all higher education students. One can assume, however, that the respondents understand the question in a broader sense and do not distinguish between university and nonuniversity higher education. Finally, the question is suboptimal as it does not include any trade-offs (e.g. the necessity to simultaneously increase taxes), because we know that reported support for policies is higher, the more abstract the question, and the less it mentions potential costs (Kangas, 1997). In sum, while the question-framing is not ideal, it offers the best possible operationalization for a cross-country and cross-temporal analysis. Future comparative surveys will hopefully include better-framed questions.

Concerning statistical methods, multilevel models are necessary because the theoretical arguments lie on different analytical levels and because individuals are nested in different groups (countries and time). Using single-level models might lead to incorrect estimates. Multilevel models can be conceived of as a form of generalized single-equation regressions; if the influence of the macro-variables is zero, multilevel models reduce to single-equation models (Gelman and Hill, 2007).

As the dependent variable is given in four answer categories ('definitely should not be', 'probably should not be', 'probably should be' and 'definitely should be'), ordinary least squares (OLS) is inappropriate and maximum-likelihood necessary; moreover, as the answer categories are rank-ordered, ordered logit models are ideal. Multinomial models could also be used, but give away the information contained in the ordering of the answer categories. Hence, multilevel ordered logit/probit is the ideal model specification. ${ }^{10}$ 


\section{Results}

\section{Descriptive overview}

Before presenting multivariate results, a brief descriptive overview on the dependent variable is given over time and across countries, to give the reader a better understanding of the phenomenon at hand. ${ }^{11}$ It is remarkable, first of all, that the distribution of answers is heavily left-skewed, that is, averaged across countries about 90 percent of the respondents are in favour of subsidies. ${ }^{12}$ This is not surprising, however, given the question-framing, which is held in very general terms and does not include any tradeoffs (as problematized above). It is striking, second, that across all countries, support for subsidies increased steadily over time (Figure B in Online Appendix). Although not a strong test yet, this finding is entirely in line with my positive feedback story.

Can we also observe differences across countries? Figure 2, depicting respondents' preferences by country, clearly answers in the affirmative. First, while the distributions are left-skewed in all countries, this is true to different degrees: in some countries (e.g. Spain), hardly anybody opposes subsidies, while 40 percent do so in Japan, the ideal-typical high-tuition-low-subsidy regime (Garritzmann, 2014: Chapter 3.4). Again, this provides initial evidence for my feedback arguments, stating that the status quo of the tuition-subsidy regime might shape attitudes. The second interesting observation from this graph are the differences in the degree of support (the height of the two bars on the right in Figure 2). For example, in all Anglo-Saxon countries, which belong to the high-tuition-high-subsidy regime (Garritzmann, 2014 and Figure 1 above), the answer category chosen the most is the second highest, that is, respondents support subsidies, but with some restraint. Continental European countries, which belong to the low-tuition-low-subsidy regime (ibid.), seem to fall in two groups: in the southern and east European systems, strong support is the answer category chosen most, while in the continental low-tuition-low-subsidy systems, the mode lies in the second highest category. Taking the risk of over-interpreting on a small-N basis, these findings indicate that the level of support for subsidies is strongly connected to the Four Worlds of Student Finance. Next, the multivariate analyses will probe these claims.

\section{Multivariate results}

Testing micro-explanations: self-interest and political attitudes. As is customary, different hierarchical models are presented, stepwise including sets of variables. I first concentrate on micro-level determinants, utilizing pooled single-level ordered logit models. Table 1 presents three models (each with and without country dummies and standard errors clustered by country): ${ }^{13}$ the first model includes only demographical aspects and variables covering materialistic self-interests. The second model adds political attitudes. The third model keeps only variables that proved significance in the former models, which does not alter the results, but increases readability and keeps the number of observations as high as possible. I comment only on the effects of major theoretical interest; readers can obtain additional information from the regression tables.

The results show that students are, as theorized in Hypothesis 1, strongly in favour of subsidies. Across models, being a student significantly and substantially increases the likelihood to support subsidies. In turn, workers, who finance subsidies by paying taxes, show much lower support: I find a robust and considerable effect of being in full-time employment across all model specifications; a similar effect exists for part-time workers, but loses significance as soon as country dummies are included. Moreover, in contrast to preferences over education spending in general (Busemeyer et al., 2009), income does have a significant negative effect on support for subsidies to lowincome students: as Hypothesis 2 claims, the higher the respondents' income, the lower their support for subsidies, presumably so because they pay disproportionately much and benefit disproportionately little. A fourth effect indicating that self-interest matters is the respondents' household composition: those living in a household without children are significantly less likely to support subsidies - possibly so, because neither they nor their children profit from these benefits (confirming Hypothesis 3). ${ }^{14}$

While some earlier studies found age-effects on education policy preferences (Busemeyer et al., 2009), neither age nor gender show significant effects in my models once political attitudes are controlled for. This is reasonable, however, because the earlier 


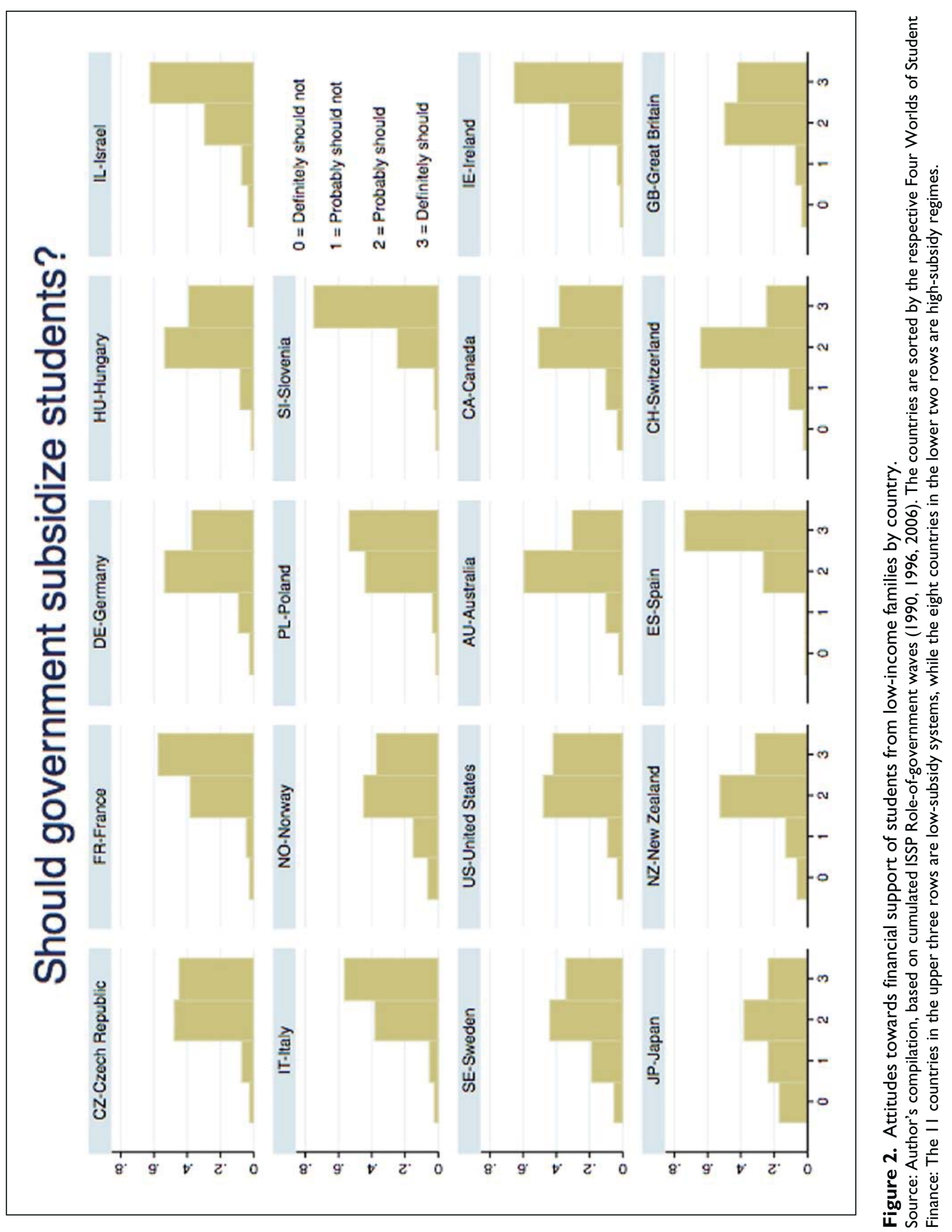


Table I. Micro-level determinants of support of students from low-income families. Ordered logit models, pooled data, odds ratios reported.

\begin{tabular}{|c|c|c|c|c|c|c|}
\hline \multirow[t]{2}{*}{ Model } & \multicolumn{2}{|c|}{ Self-interest and demographics } & \multicolumn{2}{|c|}{$\begin{array}{l}\text { Self-interest, demographics and } \\
\text { attitudes }\end{array}$} & \multicolumn{2}{|c|}{ Keep significant only } \\
\hline & $\begin{array}{l}(\mathrm{I} a) \\
\text { Random effects }\end{array}$ & $\begin{array}{l}\text { (lb) } \\
\text { Country fixed } \\
\text { effects }\end{array}$ & $\begin{array}{l}(2 \mathrm{a}) \\
\text { Random effects }\end{array}$ & $\begin{array}{l}(2 b) \\
\text { Country fixed } \\
\text { effects }\end{array}$ & $\begin{array}{l}(3 a) \\
\text { Random effects }\end{array}$ & $\begin{array}{l}\text { (3b) } \\
\text { Country fixed } \\
\text { effects }\end{array}$ \\
\hline Age & $0.999(0.35)$ & $1.001(0.42)$ & $0.999(0.39)$ & I.00I (0.67) & & \\
\hline Education (years) & $\mathrm{I} .002(0.40)$ & $1.009(0.32)$ & $1.027 * * *(0.00)$ & $1.02 \mathrm{I} * * *(0.01)$ & $\mathrm{I} .03 \mathrm{I} * * *(0.00)$ & $1.023^{* * *}(0.01)$ \\
\hline Gender (female) & $1.090 * * *(0.00)$ & $1.07 \mathrm{I} * *(0.01)$ & $0.991(0.69)$ & $0.974(0.54)$ & & \\
\hline Family income & $0.732 * * *(0.00)$ & $0.720 * * *(0.00)$ & $0.890 * * * *(0.00)$ & $0.888 * * *(0.00)$ & $0.876 * * *(0.00)$ & $0.878 * * *(0.00)$ \\
\hline Full-time worker & $0.682 * * *(0.00)$ & $0.788^{* * * *}(0.00)$ & $0.759 * * * *(0.00)$ & $0.795^{* *}(0.01)$ & $0.857 * * *(0.00)$ & $0.872^{* * *}(0.00)$ \\
\hline Part-time worker & $0.681 * * *(0.00)$ & $0.883 *(0.08)$ & $0.764 * * *(0.00)$ & $0.857^{*}(0.08)$ & $0.842 * * *(0.00)$ & $0.919(0.10)$ \\
\hline Worker (other) & $0.744 * * *(0.00)$ & $0.856 * *(0.03)$ & $0.862^{* *}(0.02)$ & $0.934(0.34)$ & & \\
\hline Retired & $0.86 \mathrm{I} * * *(0.0 \mathrm{I})$ & $0.844 * *(0.03)$ & $0.907(0.15)$ & $0.867(0.12)$ & & \\
\hline Student & $1.317 * * *(0.00)$ & $1.453 * * *(0.00)$ & $1.354 * * * *(0.00)$ & $1.492 * * *(0.00)$ & $1.332 * * *(0.00)$ & $1.508 * * * *(0.00)$ \\
\hline $\begin{array}{l}\text { Live in maximum } \\
\text { two-persons } \\
\text { household }\end{array}$ & $0.745 * * *(0.00)$ & $0.850 * * *(0.00)$ & $0.893 * * * *(0.00)$ & $0.929 * * *(0.00)$ & $0.884 * * *(0.00)$ & $0.917 * * *(0.01)$ \\
\hline $\begin{array}{l}\text { Increase public } \\
\text { education } \\
\text { spending? }\end{array}$ & & & $\mathrm{I} .85 \mathrm{I} * * * *(0.00)$ & $1.772 * * * *(0.00)$ & $1.857 * * * *(0.00)$ & $1.767 * * * *(0.00)$ \\
\hline $\begin{array}{l}\text { Should government } \\
\text { reduce income } \\
\text { differences? }\end{array}$ & & & $1.989 * * *(0.00)$ & $1.970 * * * *(0.00)$ & $2.024 * * *(0.00)$ & $1.996 * * *(0.00)$ \\
\hline $\begin{array}{l}\text { Cut government } \\
\text { spending? }\end{array}$ & & & $0.970 * * *(0.00)$ & $0.968(0.1 \mathrm{I})$ & & \\
\hline Voted far left & & & $1.458 * * * *(0.00)$ & I.247**** (0.00) & $1.388 * * * *(0.00)$ & I. $300 * * *(0.00)$ \\
\hline Voted left & & & I.207*** $(0.00)$ & I.I64*** $(0.00)$ & $1.138 * * *(0.00)$ & $1.185^{* * *}(0.00)$ \\
\hline Voted centre & & & $1.290 * * *(0.00)$ & $\mathrm{I} .038(0.49)$ & & \\
\hline Voted right & & & $0.960(0.22)$ & $0.948(0.16)$ & & \\
\hline Voted far right & & & I.335*** $(0.00)$ & $0.949(0.79)$ & & \\
\hline Voted other & & & $1.083(0.38)$ & $1.028(0.79)$ & & \\
\hline Country dummies? & No & Yes & No & Yes & No & Yes \\
\hline $\begin{array}{l}\text { Country-clustered } \\
\text { standard errors? }\end{array}$ & No & Yes & No & Yes & No & Yes \\
\hline Log-likelihood & $-47,768.87$ & $-45,761.24$ & $-31,685.46$ & $-30,730.27$ & $-32,753.68$ & $-31,739.18$ \\
\hline$N_{i}$ (respondents) & 46,974 & 46,974 & 33,842 & 33,842 & 34,974 & 34,974 \\
\hline$N_{j}$ (countries) & 18 & 18 & 17 & 17 & 17 & 17 \\
\hline
\end{tabular}

$\mathrm{P}$-values in brackets. Log-likelihood empty model $=-66,777.34$. Including dummies also for the respective ISSP-wave leaves the results unchanged, except for small changes in the third digits.

$* p<0.1, * * p<0.05$ and $* * * p<0.01$.

studies used age mainly as a proxy for 'being likely not to profit from education any more'. As my models cover this directly by the respondents' employment status, I do not expect additional age-effects. Analogously, being retired significantly decreases support for subsidies, but loses significance when we control for attitudes. In line with Hypothesis 4 socialization effects seem at work, as the likelihood of supporting subsidies increases with respondents' years in education.

Concerning political attitudes (models $2 \mathrm{a}$ and $2 \mathrm{~b}$ ), three findings are remarkable. First, as claimed in 
Hypothesis 6, those who believe it should be the government's responsibility to decrease income differences also strongly favour student aid. I theorized that this is at least partly so, because the question-framing focuses on children from low-income families, thereby emphasizing a redistributive aspect. Nevertheless, preferences towards subsidies are by far not deterministically explained by respondents' redistribution preferences. In fact, both variables correlate only medium strongly (0.40; Table A in Online Appendix). Put differently, the used ISSP question is not simply a 'redistribution-question' - many respondents hold different views on redistribution in general and on student support in particular. This, once again, emphasizes that social policies and education policies are tightly related fields, but follow different dynamics in important respects (Iversen, 2005).

Second, and adding to this reasoning, respondents supporting public education spending in general also strongly favour student support. That is, respondents tend to have rather coherent attitudes about education spending; again, however, the association is rather low (correlation: 0.27; compare Table A in Online Appendix). This indicates that respondents do hold different positions on different education policy aspects, which underlines once more the need to analyse well-framed and specific survey questions.

Third, respondents' ideological positions matter as theorized (Hypothesis 5): individuals affiliated with leftwing parties are significantly more in favour of subsidies. Respondents of the far left show the highest support, followed closely by moderate leftwing supporters. Holding centrist and far-right positions also increases the likelihood of favouring subsidies, but the effects turn insignificant once we control for country differences. Moderate rightwing supporters are significantly less in favour of subsidies. In short, political ideology has a linear effect on preferences towards supporting students, as support decreases the further to the right the individuals' position.

How large are these effects substantially? In order to make substantial interpretation of the effects easier, I estimated marginal effects, predicting the likelihood to be strongly in favour of subsidies. Due to space limitations, I summarize these briefly and refer interested readers to Table $\mathrm{B}$ in Online
Appendix. The estimations show that full-time and part-time workers are roughly 3 percent less likely to be strong supporters of subsidies, whereas students are considerably (7 percent) more likely to strongly support subsidies. Respondents living without children are 3 percent less likely to appreciate subsidies strongly. The three largest effects are found for political attitudes: a one-unit change in the degree of support for public education spending increases the likelihood to be a strong proponent of subsidies by 15 percent. Correspondingly, each step on the fourcategory scale covering redistribution preferences leads on average to a 17 percent higher likelihood that the respondent states strong support for subsidies. Finally, respondents allied with the far left are 8 percent more likely to strongly support subsidies than rightwing voters, while their centre-left comrades are 3 percent more likely. In sum, the effects of materialistic self-interest and of political attitudes are considerable and can add up to explain a huge share of the empirical variety.

To summarize, all hypothesized micro-level relationships (Hypotheses 1-6) receive empirical support: students (qua beneficiaries) are strong supporters of subsidies. Moreover, higher education increases the likelihood of supporting student support. Vice versa, respondents unlikely to benefit and those paying for the services are opposed to subsidies. Respondents appreciating redistribution and public education spending in general are much more favourable of subsidies, but neither of these attitudevariables fully determine preferences over subsidies. Finally, respondents' politico-ideological position matters greatly, as support for subsidies is much higher among leftwing voters.

Testing macro-explanations: Feedback-effects. The previous analyses demonstrated that the micro-level determinants show the theorized effects. How do the macro-variables perform? Do we find evidence for the theorized positive feedback-effects (Hypothesis 7)? Table 2 shows the influence of several macrolevel variables, controlling for those micro-level variables, which continuously proved significance (Models 3a and 3b).

Turning to the multilevel ordered logit results (Table 2), it is, first of all, vital that the micro-level 


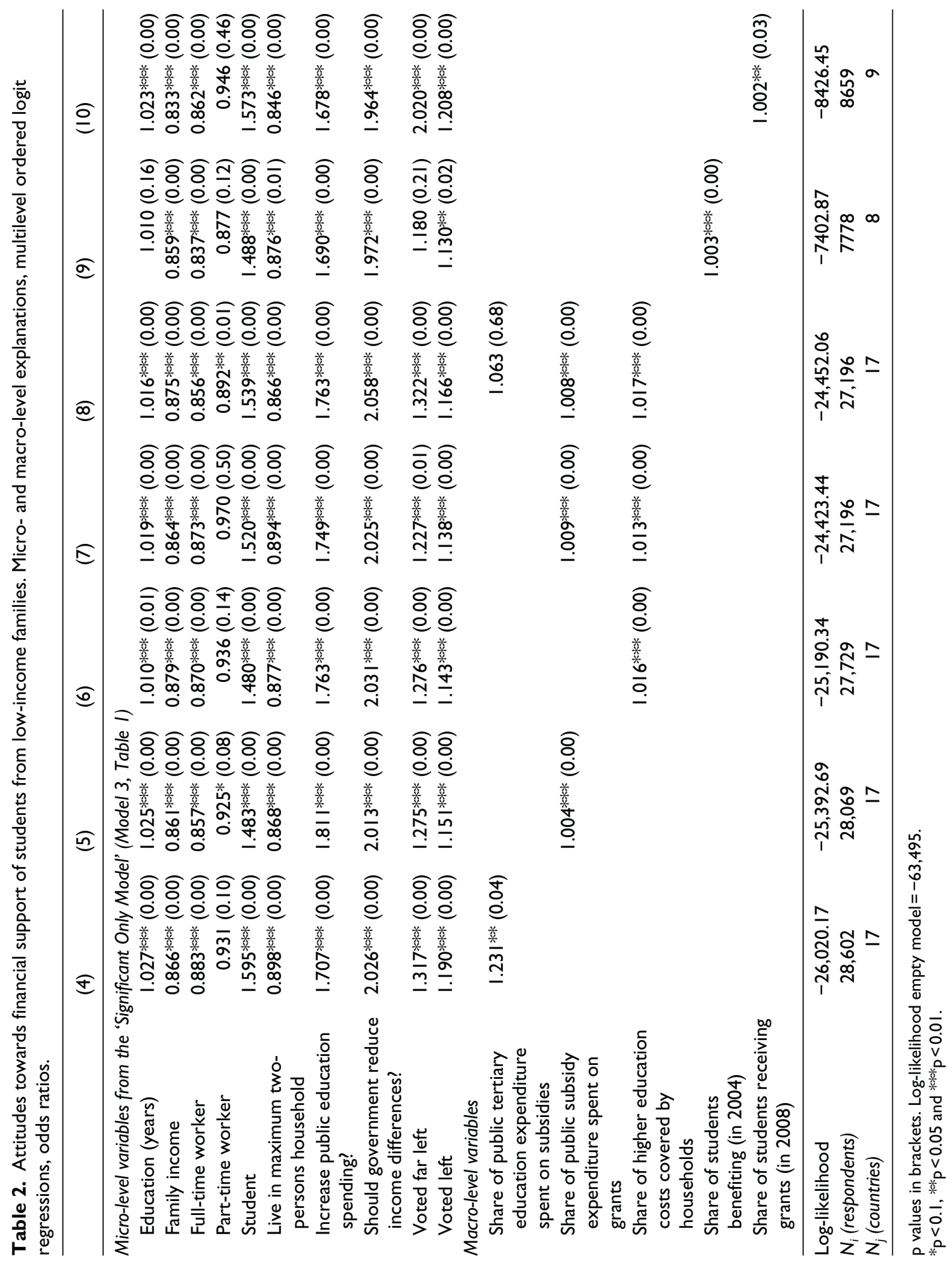


variables essentially remain unaffected by the inclusion of macro-variables - another indicator for the robustness of the micro-level results. More importantly, the macro-variables lend strong support to my arguments about positive feedback-effects: the share of countries' public tertiary education expenditure spent on student aid has a positive effect on support for this aid on the individual-level (Model 4). That is, when governments dedicate larger amounts of their higher education budget to subsidies, individual-level support for subsidies is also higher. The effect is considerable in size. As an alternative operationalization of the generosity of the subsidy system, I included public spending on grants (vis-à-vis subsidized loans) (Models 5, 7 and 8). Again, the effects point in the same direction, that is, the more generous the type of subsidies, the higher also the support for subsidies. Finally, I included the share of students receiving subsidies (Model 9) or receiving grants (model 10) as additional operationalizations of the systems' generosity: again, the estimates are highly significant and positive, indicating that public support for generous subsidies increases as the share of beneficiaries grows. Due to data availability, however, these estimates are only based on a few cases. In sum, all four operationalizations clearly indicate positive feedback-effects: the more generous the existing subsidy-regime, the larger public support for these subsidies.

To extend this article's argument, I also included variables covering the second dimension of the Four Worlds of Student Finance, that is, tuition fees (Garritzmann, 2014). It might, for example, be the case that children from low-income families are perceived as particularly needy in high-tuition countries (to enable them to cope with the tremendous costs). And indeed, the higher private education spending, the higher also support for financial aid to low-income students (Models 6-8). The effect is robust across model specifications. More importantly, however, the effects of main interest, that is, the positive feedbackeffects of the subsidy system, remain unaffected by the inclusion of variables covering the cost side.

In sum, the multilevel models suggest that positive feedback-effects are at work: support for financial assistance of low-income students is higher in countries where subsidy systems are more generous.
Placing these findings in context, I argued that these positive feedback-effects are likely to constrict parties' room for manoeuvre, because voters favour continuing along the respective regime-paths. Thus, radical policy-change over time becomes electorally more costly for parties. Consequently, the positive feedback-effects are at least part of the explanation why the Four Worlds of Student Finance persistent and prevent radical change.

\section{Robustness}

I run a large variety of robustness tests. ${ }^{15}$ I tested whether the results change when survey weights, different country selections, or different operationalizations are used. This was not the case. Moreover, results of ordered logit models are only valid if the 'ordered logit assumption' holds, that is, that the sizes and significances of the effects are the same for each difference in the answer categories (i.e. 'strongly oppose vs oppose', 'oppose vs support' and 'support vs strongly support'). As the assumption was violated for some variables, I compared the presented results to those of a partial proportional odds model. ${ }^{16}$ Put simply, a partial proportional odds model is an ordered logit model for those variables, which meet the proportional odds assumption, and a series of logit models for those variables, which do not meet the assumption. Substantially, the partial proportional odds model entirely supports the findings reported here; that is, even for those variables where the assumption was violated, the effects underline the theorized relationships. Hence, I concentrated on the ordered logit models in the main presentation.

Furthermore, I used a variety of other model specifications (e.g. ordered probit, multinomial, and logit and probit after dichotomizing the dependent variable). Of course, the results are somewhat sensitive to these changes, but the main findings remain robust. Furthermore, no serious problems of multicollinearity, non-linearity or error term distributions were detected. Some problems occurred, however, with predicting values of less frequent categories (i.e. opposition to subsidies). As this applies only to a few cases and is a frequent weakness of ordered logit models with heavily skewed distributions, however, the problem seems negligible. Finally, I 
tested for different functional forms of the effects of the independent variables (by using Stata's autofit commands), for outliers, influential cases and patterns of missing values. Again, the tests did not indicate worrisome problems. Overall, the presented results remain robust.

\section{Conclusion}

This article argued that while we begin to have a firm understanding of how collective political actors (have) shape(d) education systems (Busemeyer and Trampusch, 2011; Iversen and Stephens, 2008; Jakobi et al., 2009), our knowledge about individual education policy preferences is still crude. This is particularly true for higher education, and even more so for tuition fees and subsidies, despite their enormous distributional consequences. As long as we do not investigate attitudes empirically, however, strong assumptions have to be made in political economy analyses. Do individuals hold different preferences on education policies at all? What are the determinants of these preferences? Do leftwing and rightwing voters differ in their preferences? How are attitudes fed into the political process? Are attitudes influenced by existing institutions, and if so, via positive or negative feedback-effects?

Resulting from the lack of knowledge in these respects, several empirical facts remain puzzling, in particular the observation that no OECD-country (on the 'British exceptionalism' compare Garritzmann, 2014: Chapter 4 and footnote 3 above), has significantly altered its tuition-subsidy system during the last two or three decades. Instead, countries have further developed along their respective paths: in countries with high tuition fees, tuition fees keep rising, whereas there is no sign of tuition-fee increases in low-tuition fee countries. Likewise, high-subsidy systems expand or at least maintain their generous systems, whereas governments in low-subsidy countries make no noticeable attempts to expand support. I argued that these path dependencies can at least partly be explained by the fact that the existing tuition-subsidy regimes generate positive feedbackeffects on individual-level preferences, making it electorally costly for parties to change the status quo. Consequently, these positive feedback-effects can (at least partly) explain path dependencies in the Four Worlds of Student Finance.

In order to shed some light on these claims, this article aimed at providing a detailed analysis of individual-level preferences towards higher education finance. Empirically, I focused on attitudes towards subsidies for theoretical and empirical reasons and utilized ISSP-data for up to 22 countries over two decades. The results of multilevel ordered logit models indicate that self-interest matters: students strongly favour subsidies, while those paying for the spending, and those not expecting to benefit, oppose such aid. Second, political attitudes are important: supporters of redistribution and of public education spending in general, as well as leftwing voters are much more likely to support subsidies. Most importantly for the present purpose, I found that positive feedback-effects seem to be at work, as the existing tuition-subsidy regimes co-vary with public opinion: in systems with generous subsidy systems support for subsidies is higher. Consequently, we can deduce that these positive feedback-effects make it increasingly difficult for political parties to (radically) alter the status quo of the higher education finance system, thereby offering an explanation for path dependencies in the Four Worlds of Student Finance.

Future research could extend the analysis in several ways. First, one could investigate attitudes towards different kinds of subsidies in more detail (e.g. grants vs loans; subsidized loans vs interestcapped loans) in order to better understand the reasons why respondents support/oppose subsidies. It is, for example, possible that a respondent thinks governments should give grants to low-income students, loans to students with good grades and no support to 'average students'. By analysing more fine-grained data, we would also be able to disentangle preferences for redistribution, social policies and education policies more clearly. Second, while this article focused on subsidies, it would be worthwhile to accompany the results with an analysis of attitudes towards tuition fees. Most of the hypotheses discussed here could easily be adapted to cover these, too. Adding analyses of the 'cost side' would be highly interesting as tuition and subsidies are tightly intertwined in the Four Worlds of Student 
Finance (Garritzmann, 2014). Finally, one should delve deeper into the general link between individual-level preferences and preferences of collective political actors. How are attitudes fed into the political process? Do parties know and care about their constituencies' preferences? Under which circumstances do preferences shape outcomes (i.e. 'representative democracy') and under which conditions do institutions shape preferences (i.e. 'feedbackeffects')? Under what circumstances do we find negative feedback-effects, and when are positive feedback-effects more likely (Campbell, 2012; Kumlin and Stadelmann-Steffen, 2014)? The field of (higher) education policies seems a promising arena to analyse these fundamental political questions due to the enormous (re-)distributive dynamics in this field.

To conclude, this article is the first to systematically analyse attitudes towards financial support of higher education students and aims at deepening our understanding of the political economy of skill formation. It explains, to pick up the introduction's puzzle again, why our fictive student Hannah (and her fellow citizens) probably would have different attitudes towards higher education policies depending on where she studied and how these attitudes contribute to path dependencies in the Four Worlds of Student Finance. Many subsequent questions, however, remain to be solved.

\section{Acknowledgements}

Earlier versions of this paper were presented at the ESPAnet doctoral-workshop in Mannheim, at the CESconference in Amsterdam, and at Harvard's Research Workshop in Comparative Politics. I am grateful to the participants' constructive input. I also received very valuable feedback from four anonymous reviewers as well as from the editors. Moreover, I wish to thank Michael Braun, Marius Busemeyer, Torben Iversen, John Marshall, Paul Marx, Traute Meyer, Leonce Röth, Wim Van Oorschot, and Claus Wendt. Lina Seitzl provided excellent research assistance.

\section{Funding}

Julian Garritzmann received - and gratefully acknowledges - financial support from the German Research Foundation's Emmy-Noether-programme (Grant No. BU 1852/4-1).

\section{Notes}

1. In the following expressions, 'subsidies', 'student support' and 'financial assistance of students' are used synonymously, indicating public spending directly to students.

2. The Four Worlds can also be found when considering different operationalizations (e.g. spending as a share of GDP, spending on grants, household spending as a share of GDP and many others) or when utilizing multivariate techniques (e.g. cluster analyses) (Garritzmann, 2014: Chapter 2).

3. The noteworthy exception is England, where tuition fees of $£ 1000$ were installed in 1997 and have recently been raised to $£ 9000$. Yet, even this exceptional case underlines my arguments as it shows, first, that radical change in the tuition-subsidy systems has become a clear exception to the rule, as the British case led to much debate domestically and internationally and remains unparalleled in the OECD-world (on the 'British Exceptionalism' compare Garritzmann, 2014: Chapter 4). Radical policy-change was feasible in Britain because - to make a long story short - the Conservatives had skilfully prepared the ground for the introduction of fees by repeatedly emphasizing that the quality of higher education might deteriorate in a time of fiscal austerity but rising student numbers. In line with these arguments, a non-partisan committee, commissioned in 1996 by then Prime Minister John Major (Conservatives), famously proposed to introduce means-tested tuition fees, accompanied by means-tested grants and subsidized student loans ('Dearing Report'). In 1997, the Labour government under Prime Minister Tony Blair opted to follow these recommendations and installed means-tested annual tuition of $£ 1000$ with the goal to continue expanding access to higher education while maintaining the quality of teaching and research without the necessity to increase general taxes. This decision led to much dispute within the party and its constituency and potentially contributed to Labour's worsening election results over the following years (the LibDems have recently had a similar experience when they flipped from a fierce anti-tuition to a pro-tuition position). The British case thus illustrates very well, second, that - in line with my arguments - radical policy-change is not entirely impossible but that positive feedbackeffects on the mass-public level make departure from the respective regime-paths politically difficult and electorally costly for political parties.

4. A much broader literature exists in the US-context, focusing particularly on feedback-effects of education 
systems, for example, on civil engagement (Mettler, 2002; Mettler and Welch, 2004). Furthermore, and in some ways related, but concerned with different phenomena, is a broad sociological literature on determinants of individuals' education decisions. Yet, as the article focuses on policy preferences of individuals and on internationally comparative studies, these related investigations are disregarded.

5. Empirically, this is operationalized as respondents living in a single- or two-person household (discussed below).

6. I disregard Pierson's third category, feedback-effects on interest groups, because these are less relevant in the case of higher education finance. For a noteworthy exception, however, see Mettler's (2010) analysis of the US case, demonstrating why positive feedback-effects on interest groups, particularly the banking sector, were crucial in this case.

7. As it is easier to make rational choice arguments about the second dimension of the Four Worlds of Student Finance, namely, tuition fees, focusing on subsidies in the empirical analysis even provides the 'stronger test' (Van Evera, 1997: 30ff) for my feedback arguments, which is the theoretical reason why the empirical analysis focuses on subsidies.

8. I also included additional variables, for example, religious affiliation and frequency of church attendance as these have been found to affect individual (social) policy preferences. Yet, as this did not affect the main results, I omit them in the main presentation due to space limitations. Results are available on request.

9. I thank Paul Marx and Carsten Jensen for pointing this out to me.

10. The empirical analyses were established utilizing Stata 13's 'meologit' and related commands.

11. Table A in Online Appendix provides a summary of the included variables and their respective bivariate correlations with the dependent variable.

12. While problematic for OLS, this distribution should not lead to estimation problems in my multivariate analyses, as ordered logit models do not make any assumptions that are violated by this (compare Section 'Robustness').

13. Results of non-pooled analyses by country, by timepoint and by country-year are available on request. I also tested whether including time-dummies changes the results of these micro-level variables. This is not the case. That is, the micro-variables have surprisingly constant effects over time. I do not comment on minor changes here due to reasons of space availability.
14. As no direct measure for 'having children in education' was available, the used proxy 'living in a singleor two-person household' even underestimates the true effect, because it might include many parents, who live in a two-person household because they attend higher education institutions and no longer live at home.

15. I comment here only briefly on the major tests and offer a commented do-file on request.

16. Using Stata's 'gologit2.ado' with the 'autofit' option (Williams, 2006).

\section{References}

Ansell, B.W. (2010) From the Ballot to the Blackboard: The Redistributive Political Economy of Education. New York: Cambridge University Press.

Archer, L., Hutchings, M. and Ross, A. (2003) Higher Education and Social Class: Issues of Inclusion and Exclusion. London and New York: RoutledgeFalmer.

Blossfeld, H.P. and Shavit, Y. (1993) Persistent Inequality: Changing Educational Attainment in Thirteen Countries. Boulder, CO: Westview Press.

Boix, C. (1997) 'Political Parties and the Supply Side of the Economy: The Provision of Physical and Human Capital in Advanced Economies, 1960-90', American Journal of Political Science 41(3): 814-45.

Breen, R. and Jonsson, J.O. (2005) 'Inequality of Opportunity in Comparative Perspective: Recent Research on Educational Attainment and Social Mobility', Annual Review of Sociology 31: 223-43.

Brooks, C. and Manza, J. (2006a) 'Social Policy Responsiveness in Developed Democracies', American Sociological Review 71(3): 474-94.

Brooks, C. and Manza, J. (2006b) 'Why Do Welfare States Persist?', Journal of Politics 68(4): 816-27.

Busemeyer, M.R. (2009) 'Social Democrats and the New Partisan Politics of Public Investment in Education', Journal of European Public Policy 16(1): 107-26.

Busemeyer, M.R. (2012) 'Inequality and the Political Economy of Education: An Analysis of Individual Preferences in OECD Countries', Journal of European Social Policy 22(3): 219-40.

Busemeyer, M.R. and Jensen, C. (2012) 'The Impact of Economic Coordination and Educational Institutions on Individual-level Preferences for Academic and Vocational Education', Socio-Economic Review 10(3): 525-47.

Busemeyer, M.R. and Trampusch, C. (2011) 'Review Article: Comparative Political Science and the Study of Education', British Journal of Political Science 41: 413-43. 
Busemeyer, M.R., Cattaneo, M.A. and Wolter, S.C. (2011) 'Individual Policy Preferences for Vocational versus Academic Education: Microlevel Evidence for the Case of Switzerland', Journal of European Social Policy 21(3): 253-73.

Busemeyer, M.R., Franzmann, S.T. and Garritzmann, J.L. (2013) 'Who Owns Education? Cleavage Structures in the Partisan Composition over Educational Expansion', West European Politics 36(3): 521-46.

Busemeyer, M.R., Goerres, A. and Weschle, S. (2009) 'Attitudes Towards Redistributive Spending in an Era of Demographic Ageing: The Rival Pressures from Age and Income in 14 OECD Countries', Journal of European Social Policy 19(3): 195-212.

Callender, C. and Jackson, J. (2005) 'Does the Fear of Debt Deter Students From Higher Education?', Journal of Social Policy 34: 509-40.

Campbell, A.L. (2012) 'Policy Makes Mass Politics', Annual Review of Political Science 15: 333-51.

Castles, F.G. (1982) 'The Impact of Parties on Public Expenditure', in F.G. Castles (ed.) The Impact of Parties: Politics and Policies in Democratic Capitalist States, pp. 21-96. London: Sage.

Curs, B.R., Singell, L.D. and Waddell, G.R. (2007) 'The Pell Program at Thirty Years', in J.C. Smart (ed.), Higher Education: Handbook of Theory and Research, pp. 281-334. Dordrecht: Springer.

Esping-Andersen, G. (1990) The Three Worlds of Welfare Capitalism. Cambridge: Polity Press.

Estevez-Abe, M., Iversen, T. and Soskice, D. (2001) 'Social Protection and the Formation of Skills: A Reinterpretation of the Welfare State', in P.A. Hall and D. Soskice (eds) Varieties of Capitalism: The Institutional Foundations of Comparative Advantage, pp. 145-83. Oxford: Oxford University Press.

Fernández, J.J. and Jaime-Castillo, A.M. (2013) 'Positive or Negative Policy Feedbacks? Explaining Popular Attitudes Towards Pragmatic Pension Policy Reforms', European Sociological Review 29(4): 803-15.

Fernandez, R. and Rogerson, R. (1995) 'On the Political Economy of Education Subsidies', The Review of Economic Studies 62(2): 249-62.

Garritzmann, J.L. (2014) The Political Economy of Higher Education Finance. A Comparative Analysis of the Politics of Tuition Fees and Subsidies. PhD thesis, University of Konstanz, Konstanz.

Gelman, A. and Hill, J. (2007) Data Analysis Using Regression and Multilevel/Hierarchical Models. Cambridge: Cambridge University Press.
Hall, P.A. and Soskice, D. (2001) Varieties of Capitalism: The Institutional Foundations of Comparative Advantage. Oxford: Oxford University Press.

Huber, E. and Stephens, J.D. (2001) Development and Crisis of the Welfare State: Parties and Policies in Global Markets. Chicago, IL: University of Chicago Press.

ISSP Research Group. (2008) 'International Social Survey Programme: Role of Government I-IV - ISSP 19851990-1996-2006', GESIS Data Archive, Cologne. ZA4747 Data file Version 1.0.0.

Iversen, T. (2005) Capitalism, Democracy, and Welfare. Cambridge: Cambridge University Press.

Iversen, T. and Stephens, J.D. (2008) 'Partisan Politics, the Welfare State, and Three Worlds of Human Capital Formation', Comparative Political Studies 41(4-5): 600-37.

Jacobs, A.M. and Weaver, R.K. (2014) 'When Policies Undo Themselves: Self-Undermining Feedback as a Source of Policy Change', Governance: An International Journal of Policy, Administration, and Institutions. Epub ahead of print 10 July 2014. DOI: 10.1111/gove.12101.

Jakobi, A.P., Martens, K. and Wolf, K.D. (eds) (2009) Education in Political Science: Discovering a Neglected Field. Abingdon: Routledge.

Jensen, C. (2011) 'Capitalist Systems, Deindustrialization, and the Politics of Public Education', Comparative Political Studies 44(4): 412-35.

Kangas, O.E. (1997) 'Self-Interest and the Common Good: The Impact of Norms, Selfishness and Context in Social Policy Opinions', The Journal of SocioEconomics 26(5): 475-94.

Kenworthy, L. (2009) 'The Effect of Public Opinion on Social Policy Generosity', Socio-Economic Review 7(4): 727-40.

Kumlin, S. and Stadelmann-Steffen, I. (2014) How Welfare States Shape the Democratic Public. Policy Feedback, Participation, Voting, and Attitudes. Cheltenham: Edward Elgar.

McPherson, M. and Schapiro, M.O. (2006) 'US Higher Education Finance', in E.A. Hanushek and F. Welch (eds) Handbook of the Economics of Education, vol. 2, pp. 1403-34. North Holland: Elsevier.

Martin, A. and Lehren, A.W. (2012) 'A Generation Hobbled by the Soaring Cost of College. The New York Times, 12 May, available at www. nytimes.com/2012/05/13/business/student-loansweighing-down-a-generation-with-heavy-debt. $\mathrm{html}$ ?pagewanted=alland_r=0andpagewanted=print. 
Mettler, S. (2002) 'Bringing the State back in to Civic Engagement: Policy Feedback Effects of the GI Bill for World War II Veterans', American Political Science Review 96(2): 351-65.

Mettler, S. (2010) 'Reconstituting the Submerged State: The Challenges of Social Policy Reform in the Obama Era', Perspectives on Politics 9: 803-24.

Mettler, S. and Welch, E. (2004) 'Civic Generation: Policy Feedback Effects of the GI Bill on Political Involvement over the Life Course', British Journal of Political Science 34: 497-518.

Müller, W.C. and Strøm, K. (1999) Policy, Office, or Votes? How Political Parties in Western Europe Make Hard Choices. Cambridge: Cambridge University Press.

Nakata, Y. and Mosk, C. (1987) 'The Demand for College Education in Postwar Japan', Journal of Human Resources 22(3): 377-404.

Organisation for Economic Co-operation and Development (OECD). (2013) 'Education at a Glance: OECD Indicators'. OECD Publishing, available at http:// dx.doi.org/10.1787/eag-2013-en.

Pierson, P. (1993) 'When Effect Becomes Cause: Policy Feedback and Political Change', World Politics 45(4): 595-628.

Pierson, P. (1994) Dismantling the Welfare State? Reagan, Thather, and the Politics of Retrenchment. Cambridge: Cambridge University Press.

Pierson, P. (2000) 'Increasing Returns, Path Dependencies, and the Study of Politics', The American Political Science Review 94(2): 251-67.

Pierson, P. (2005) 'The Study of Policy Development', Journal of Policy History 17: 24-51.

Pierson, P. (2006) 'Public Policies as Institutions', in I. Shapiro, S. Skowronek and D. Galvin (eds) Rethinking Political Institutions: The Art of the State, pp. 114-31. New York: New York University Press.

Rehm, P. (2011) 'Social Policy by Popular Demand', World Politics 63(2): 271-99.

Schmidt, M.G. (2007) 'Testing the Retrenchment Hypothesis: Education Spending, 1960-2002', in F.G. Castles (ed.) The Disappearing State?
Retrenchment Realities in an Age of Globalisation, pp. 159-83. Cheltenham: Edward Elgar.

Skocpol, T. (1992) Protecting Soldiers and Mothers: The Political Origins of Social Policy in the United States. Cambridge, MA: The Belknap Press of Harvard University Press.

Soroka, S.N. and Wlezien, C. (2010) Degrees of Democracy: Politics, Public Opinion, and Policy. Cambridge: Cambridge University Press.

Stegmueller, D. (2013) 'How Many Countries for Multilevel Modeling? A Comparison of Frequentist and Bayesian Approaches', American Journal of Political Science 57(3): 748-61.

Thelen, K. (1999) 'Historical Institutionalism in Comparative Perspective', Annual Review of Political Science 2: 369-404.

Thelen, K. (2004) How Institutions Evolve: The Political Economy of Skills in Germany, Britain, the United States, and Japan. Cambridge: Cambridge University Press.

Van Evera, S. (1997) Guides to Methods for Students of Political Science. Ithaca, NY: Cornell University Press.

Van Oorschot, W. (2006) 'Making the Difference in Social Europe: Deservingness Perceptions among Citizens of European Welfare States', Journal of European Social Policy 16(1): 23-42.

Weaver, K. (2010) 'Paths and Forks or Chutes and Ladders? Negative Feedbacks and Policy Regime Change', Journal of Public Policy 30(2): 137-62.

Williams, R. (2006) 'Generalized Ordered Logit/Partial Proportional Odds Models for Ordinal Dependent Variables', Stata Journal 6(1): 58-82.

Windolf, P. (1997) Expansion and Structural Change. Higher Education in Germany, the United States, and Japan, 1870-1990. Boulder, CO: Westview Press.

Wlezien, C. (1995) 'The Public as Thermostat: Dynamics of Preferences for Spending', American Journal of Political Science 39(4): 981-1000.

Wlezien, C. and Soroka, S.N. (2012) 'Political Institutions and the Opinion-Policy Link', West European Politics 35(6): 1407-32. 